\title{
DATA-DRIVEN RIGHTSIZING: INTEGRATING PRESERVATION INTO THE LEGACY CITIES LANDSCAPE
}

\author{
Emilie Evans ${ }^{a}$, Briana Grosicki ${ }^{b}$ \\ a Director of the Rightsizing Cities Initiative, PlaceEconomics, PO Box 7529, Washington, DC $20044-$ \\ eevans@placeeconomics.com \\ ${ }^{\mathrm{b}}$ Director of Research, PlaceEconomics, PO Box 7529, Washington, DC 20044 - bgrosicki@placeeconomics.com
}

KEY WORDS: Historic preservation, heritage conservation, legacy cities, rightsizing, survey, data, rapid mobile surveying

\begin{abstract}
:
Legacy cities, whose built environments are undergoing transformations due to population loss, are at a critical juncture in their urban history and the historic preservation field has an important role to play. Rapid mobile surveys provide an opportunity for data collection that expands beyond traditional historic criteria, and positions preservationists to be proactive decision-makers and to align with multi-disciplinary partners. Rapid mobile surveys are being utilized in conjunction with in-depth data analysis of comprehensive livability metrics at the parcel, neighborhood, and citywide levels to develop recommendations for reactivating vacant properties. Historic preservationists are spearheading these efforts through a tool called Relocal, which uses 70-85 distinct metrics and a community priority survey to generate parcel-level recommendations for every vacant lot and vacant building in the areas in which it is applied. Local volunteer-led rapid mobile surveys are key to gathering on-the-ground, real-time metrics that serve as Relocal's foundation. These new survey techniques generate usable data sets for historic preservation practitioners, land banks, planners, and other entities to inform strategic rightsizing decisions across legacy cities.
\end{abstract}

\section{INTRODUCTION}

New approaches to data collection using smart technology are enabling heritage and land use practitioners as well as civic leaders to analyze, understand, and plan for their communities in a transparent environment (Powe, 2014). In cash-strapped legacy cities that are undergoing transformation due to population loss, data-driven land use planning is even more imperative. Of primary concern to legacy city stakeholders is an overabundance of vacant building stock, much of which is over 50 years old and contains character-rich, historic fabric (The Advisory Council on Historic Preservation, 2014). Preservation practitioners in these cities, who bring a wealth of knowledge centered on identifying and assessing characteristics of the built environment, are positioned to aid in decision-making around where investment - in rehabilitation and demolition - makes sense. In the face of legacy city challenges, however, traditional historic preservation assessment criteria, as well as time-consuming data collection methods, can isolate preservation practitioners. As a result, preservationists miss opportunities to collaborate in shaping demolition and other land use decisions. To play an active role, preservation-oriented data collection that provides relevant metrics to planners, land bank officials, and other decision-makers must be gathered and effectively integrated into broader planning efforts. A recent crop of preservationists are rising to meet this important challenge, undertaking new rapid survey methods intended to produce more extensive data sets efficiently using smart technology.

\section{MAIN BODY}

\subsection{Traditional Historic Resource Survey Model}

Historic resource surveys have long been an important method by which preservation entities inventory historic architectural assets. Primarily, these efforts are carried out with the intent to determine eligibility for historic designation at the local, state, or national levels and the resulting data sets are managed by the city or statewide preservation agencies. The National Register Criteria, which focuses on buildings at least 50 years old, serves as the national standard when assessing properties for potential designation (Nps.gov, 2015). These criteria establish a property's value on a building-by-building basis through the lens of its association with key historical dates, people or events of significance, or unique architectural features or styles.

Traditional historic resource surveys have, historically, involved lengthy amounts of time in the field with professional surveyors encumbered by paper, pen, and often a historic map for reference while taking notes on architectural styles and historic integrity as well as photographing or sketching the properties. Recently, methods for capturing traditional historic survey data have advanced technologically, creating electronic platforms to encourage speedier data collection in the field. ${ }^{1}$ Increasingly, preservation organizations across the country are expanding survey methodologies to include greater community input in an effort to more broadly understand places of import to local residents. ${ }^{2}$

These data sets are valuable. Collecting and utilizing this data supports preservation advocacy efforts and is the basis for his-

1 The National Park Service's Cultural Resources GIS Facility and its Certified Local Government (CLG) program teamed up with the City of Alexandria, Virginia in 2014 to test and develop a mobile architectural survey web-based platform that can serve as a national standard for historic resource surveying (Oaks 2014).

2 The City of Denver and Historic Colorado partnered with Historic Denver to undertake Discover Denver, a surveying and social media effort to identify the city's historic resources. The survey relies on traditional documentation techniques to field survey each property along with crowd-sourced information for local residents. The pilot survey areas were completed in late 2014 (Discoverdenver.co 2015). 
toric designations for individual sites and districts. Historic designations can unlock financial incentives to support redevelopment, such as federal or state historic preservation tax credits, or provide protection for these structures through oversight by a local historic district commission, or both (Preservation.org, 2015). But data sets resulting from these traditional surveys that use National Register Criteria as their basis have a limited scope and their intention is primarily to support historic designations and to develop a data-based foundation for preservation-planning. Preservation efforts that are not "connected to the overall decision-making about a city's economic development, public investment, and urban form - is ineffective and won't bring the desired results (Mason 2009, 39).”

While National Register Criteria may have limited relevance beyond historic designation, assessments within the traditional historic resource survey models - such as architectural integrity, neighborhood character, and historic context - are germane to other disciplines. Integrity, specifically, speaks to "the ability of a property to convey its significance" through retention of original features, setting, and neighborhood (Nps.gov 2015). Connections between these aspects of the built environment and qualities intrinsic to successful neighborhood development from a planning perspective are not difficult to find. The American Planning Association describes "design and architectural features that are visually interesting" as directly supporting and contributing to great neighborhood character and Richard Florida's writing on creating quality places emphasizes the need for authenticity of buildings and history (Planning.org 2015; Florida 2012). Thus, elements like architectural integrity and neighborhood character can be highly relevant to other disciplines that deal with the built environment such as planners, developers, and land bank staff when determining a future course for buildings. It is incumbent upon preservation practitioners to help effectively translate these elements of the traditional historic preservation lexicon into collectable and transferable data points that are relevant to other planning efforts. To this end, the preservation field has an opportunity to expand the relevance of established metrics while contributing additional data points through effective collection efforts in order to assist partners in making land use decisions on the ground.

\subsection{Data-Based Preservation Efforts In Legacy Cities}

In legacy cities, which are addressing an abundance of vacant building stock, data collection - specifically on the built environment - plays an important role. "Legacy city" is a term used to describe urban communities with "rich histories and assets" that "have struggled to stay relevant in an ever-changing global economy (The American Assembly 2011, 0)." These older cities flourished at the height of the industrial revolution and served as hubs of manufacturing, commerce, and business. Over the last few decades, due to "significant population and job loss," legacy cities have experienced dwindling tax bases, disinvestment in city infrastructure, and swaths of vacant and abandoned building stock in addition to "high residential vacancy and diminished service capacity and resources (Legacycities.org 2015)." Legacy cities have lost between $20-70 \%$ of their populations since 1950 (Legacycities.org 2015).

These trends are due, in part, to a combination of socio-economic transformations: suburbanization, deindustrialization, racial tensions, and redlining, along with many other factors. The recent (and ongoing) foreclosure crisis compounded the effects of these trends, and has left many legacy cities reeling across the Midwest, Mid-Atlantic, and Northeast regions (Mallach and Brachman 2013). While Detroit, Cleveland, Buffalo, and St. Louis arise as easily identifiable examples, they share the list of top 50 legacy cities with Scranton, Utica, Louisville, and Newark (Legacycities.org 2015). In some cases, growing cities -- such as Little Rock, AR or Chicago, IL -- have neighborhoods facing the same array of challenges as legacy cities. Today, legacy city communities and neighborhoods small and large are facing difficult and important decisions around their built environment - where to reinvest, where to focus demolition, and how to spend limited resources effectively.

Among their many assets, legacy cities are filled with historic buildings, walkable tree-lined neighborhoods, and are situated on lakes and riverfronts (American Assembly 2011, 5). Property values and foreclosure rates in historic districts have remained more stable than in comparable neighborhoods throughout the recent recession (Kostyu 2008; Broadbent 2011; Rypkema and Paxton 2015). A recent data-based study by the Preservation Green Lab reviewed economic, social, and environmental metrics over building maps and found neighborhoods with a mix of older, smaller buildings score higher than areas of larger, newer structures (Preservation Green Lab 2014, 1). Tom Mayes, Deputy General Counsel for the National Trust for Historic Preservation, has written a series of essays on why old places matter, in which he states, "People in a community share a sense of its identity and character, which is often represented by the old places that serve as community landmarks (Mayes 2015)." The historic, character-rich and culturally significant building stock, abundant in legacy neighborhoods, is a critical asset for these communities to build on and leverage in long-term plans moving forward.

However, not all buildings can or should be saved. This is acknowledged even within the preservation field (Bertron 2013). Effective rightsizing strategies must entail a balance of strategic neighborhood interventions, from preservation and rehabilitation to mothballing to deconstruction and demolition (Bertron 2013). Rightsizing is generally referred to as the "process of change" and planning a city must do to "recalibrate" after significant population loss and resulting outcomes (The Advisory Council on Historic Preservation 2014, 1). Rightsizing entails tailoring a city's infrastructure, footprint, and city services to align with its current and projected population (Bertron 2013). It is a term - distinct from the related term, "shrinking cities" - that implies that every city has a "right size," and that the process of adjustment to achieve that shape is a proactive planning approach for each city's unique size and shape, not a journey of shrinkage and decline.

While demolition is a necessary part of any rightsizing strategy, it is a tool that must be used strategically and in conjunction with other interventions on vacant properties. In 2012, Alan Mallach, then a senior fellow at the Metropolitan Policy Program with the Brookings Institution, agreed, stating: "Given both the critical need for large-scale demolition in many older communities, the costs associated with it, and the limited resources available, policymakers and practitioners need to be strategic in their decisions about which buildings to demolish, and in what areas... (5)"

Increasingly, city agencies, land banks, and other decision-makers in legacy cities are turning to data to guide strategies within a rightsizing and legacy city framework, especially around demo- 
lition and reinvestment (Dale 2013). This data is being collected using smart technology in speedy and efficient ways, and incorporating data from across disciplines to spur informed decisions. Oftentimes, this data is held in an online platform for greater transparency and cross-discipline utility of the data

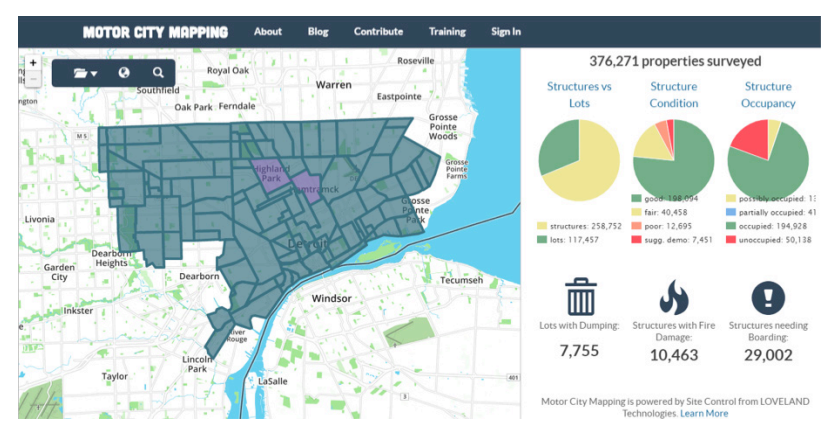

Figure 1. Screenshot of Detroit's Motor City Mapping interactive website, a result of the Data Driven Detroit initiative

(Source: Motor City Mapping, 2017)

Heritage metrics -- such as architectural character or integrity, construction quality, and building condition -- have a strong role to play in guiding decision-making through data. These characteristics and assessments provide vital information on which to base decisions regarding demolition or other interventions, such as deconstruction or mothballing. But heritage-based metrics alone do not paint a full and complete picture of the viability and stability of blocks and neighborhoods. These heritage- and building-oriented metrics must be analyzed in conjunction with an array of other metrics that help decision-makers understand the livability of areas at multiple levels.

For example, in Detroit, Michigan, the 2013-2014 Motor City Mapping survey - led by Loveland Technologies, Data Driven Detroit, and the Detroit Blight Task Force - surveyed every parcel of land in the city in order to get a handle on current conditions for both lots and structures. Using tablets in the field, over 100 surveyors logged data for roughly 380,000 parcels over the course of two months (Austen 2014). Questions included whether property was open and in need of boarding, whether there was dumping on site, and what the building condition was. The resulting data was layered with fire department incidents, water shut-offs, postal service, and other data sets, which informed decisions by the Detroit Land Bank Authority and other entities.

To add a preservation-based data layer to Motor City Mapping, the Michigan Historic Preservation Network and Preservation Detroit teamed up to lead the Detroit Historic Resource Survey (DHRS). Nearly 50 volunteers used smartphones to gather information on architectural integrity, neighborhood character, and block intactness for nearly 18,000 vulnerable historic buildings in Detroit in order to provide a complementary data set to Motor City Mapping to inform demolition decisions in Detroit. The Detroit Land Bank Authority -- who ultimately made those demolition decisions -- utilized the DHRS data layer along with Motor City Mapping, and the DHRS data is now mapped openly on Data Driven Detroit's website.

In 2015 in Muncie, Indiana, the Historic Preservation Commission initiated a citywide rapid mobile survey titled ScoutMuncie. Muncie had not had a traditional historic resource survey since 1985 and was not scheduled to again until 2021. Preservation,

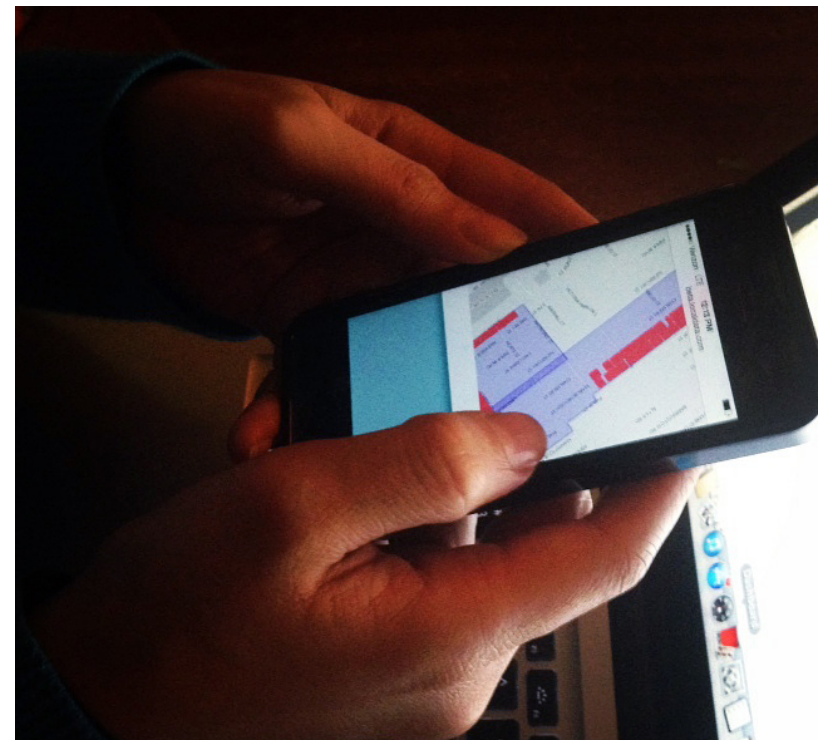

Figure 2. DHRS surveyor using her smartphone to monitor survey results coming in from other surveyors in the field (Photo Credit: Amy Elliott Bragg)

demolition, and other land use decisions were being made based on outdated information. ScoutMuncie's intention was to gather needed information on every building in the city, including architectural character and building condition (ScoutMuncie, 2016). The survey captured heritage- and building-based metrics, and used the data for future historic designations, but also an array of data that informs other city agencies and decision-makers including sidewalk condition and illegal dumping. This project recognizes that data is critical to informing city and neighborhood decisions and preservation is one element in maintaining a vibrant, healthy city -- and that preservation entities can be the initiators and leaders of these projects.

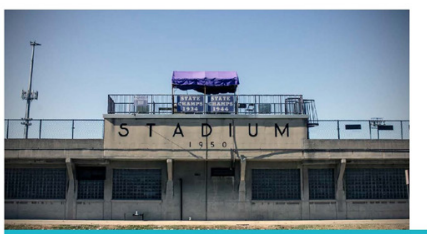

ZONE 4

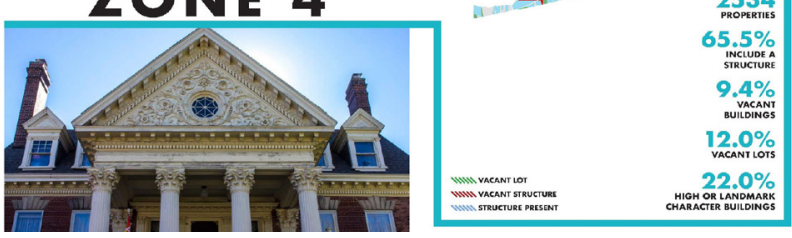

Figure 3. Results of ScoutMuncie for the downtown area of Muncie illustrating the percentage of unproductive properties (vacant buildings and vacant lots) and wealth of architecturally significant resources within (Source: ScoutMuncie, 2017)

In these examples, preservation practitioners took a proactive lead in collecting data on the older built environments of their cities to gather both preservation and non-preservation oriented data through rapid mobile surveys. These legacy cities, among others, are proactively engaging in ground-level data collection and the resulting data sets are informing strategic rightsizing decisions affecting the built environment. 
Historic preservation practitioners are positioned to aid in the development of such metrics and even in their collection alongside land banks, planning agencies, and neighborhood groups. Innovative thinkers in the field recognize that swift collection of data allows preservation practitioners "to develop and implement new survey tools that use smartphones and tablets to catalog resources," "creates new opportunities to demonstrate how older buildings support sustainability and vitality," and "can be used to present information about the historic resources of communities in novel, alluring ways that engage large public audiences (Powe 2014).”

Largely, though, historic preservation's role within rightsizing initiatives - in particular around demolition decisions - has been relegated to responding to local historic properties up for demolition or Section 106 review of properties flagged when federal funding is used for the same purpose. This positioning consigns preservation practitioners to be reactive to projects already in development pipeline. From a regulatory perspective, an approval from the preservation agency is seen solely as a checkbox needed to move forward with denial perceived as preservationists standing in the way of progress. In these scenarios, the relevance of historic preservation in a rightsizing and legacy city context is questioned and its practitioners excluded from earlier inclusion in broader decision-making efforts. Using new data points and collection methods, preservationists stand to play a more proactive role helping to inform decisions around these interventions as part of broader rightsizing strategies.

\subsection{Relocal And The Role Of Preservation And Rapid Mo- bile Surveys In Holistic Neighborhood Analysis}

Entities within Muncie, Indiana; Cincinnati, Ohio; and Little Rock, Arkansas sought assistance collecting data and developing strategies for dealing with vacant and abandoned properties through Relocal, a data-based tool developed by the Rightsizing Cities Initiative at PlaceEconomics in 2012. Relocal offers parcel- and neighborhood-level recommendations for integrating vacant and abandoned properties into long-range revitalization plans (Bertron and Rypkema 2015). Relocal utilizes between 70-85 distinct metrics -- depending on the availability of sets -- including data points from a volunteer-driven rapid mobile field survey and a community priority survey in order to analyze neighborhood strengths and challenges.

The rapid mobile field survey, which utilizes a web-based survey platform, collects data on building condition, architectural character, building quality, vacant lot usage, graffiti, and more. Additional data metrics Relocal utilizes range from voter registration and density potential to sidewalk condition and public transportation to household purchasing power and foreclosures. These comprehensive metrics are grouped across eight categories that include Real Estate, Stability, Neighborhood Character, Walkability, Fiscal Responsibility, Economic Opportunity, Engagement, and Environment. The community priority survey is distributed to local residents through organizations on the ground and identifies which neighborhood characteristics residents value most. These results are then weighted in the backend analysis used to inform recommendations (Bertron and Rypkema 2015).

This wide range of comprehensive metrics incorporates heritage-based elements into a broader matrix that assesses myriad pieces that go together to make parcels, blocks, and neighborhoods viable, stable, and desirable places to live, work, and play.
The subsequent analysis of all metrics plus the community priority survey yields parcel-level recommendations for every vacant building and vacant lot in the study areas within the cities where it is applied. For vacant buildings, recommendations include rehabilitation, stabilization, demolition/deconstruction, and defer decision. For vacant lots, recommendations include infill construction, environmental reuse, contributory reuse (such as a pocket park or side lot split), and defer decision (Rightsizing Cities Initiative, PlaceEconomics 2015). For both vacant buildings and lots, "defer decision" suggests that no clear recommendation emerged for these properties at that time, and in addition, limited funding will be well spent on the three other recommendation categories.

Muncie served as Relocal's pilot project and, in partnership with the City of Muncie and Ball State University's Historic Preservation Program, PlaceEconomics analyzed five neighborhoods across the city. A team of ten trained volunteers surveyed over 4,000 properties in three days utilizing LocalData's web-based smartphone survey platform to gather data on the built environment. The City of Muncie Historic Preservation Commission and neighborhood groups are using the neighborhood-level findings and recommendations to inform decision-making.
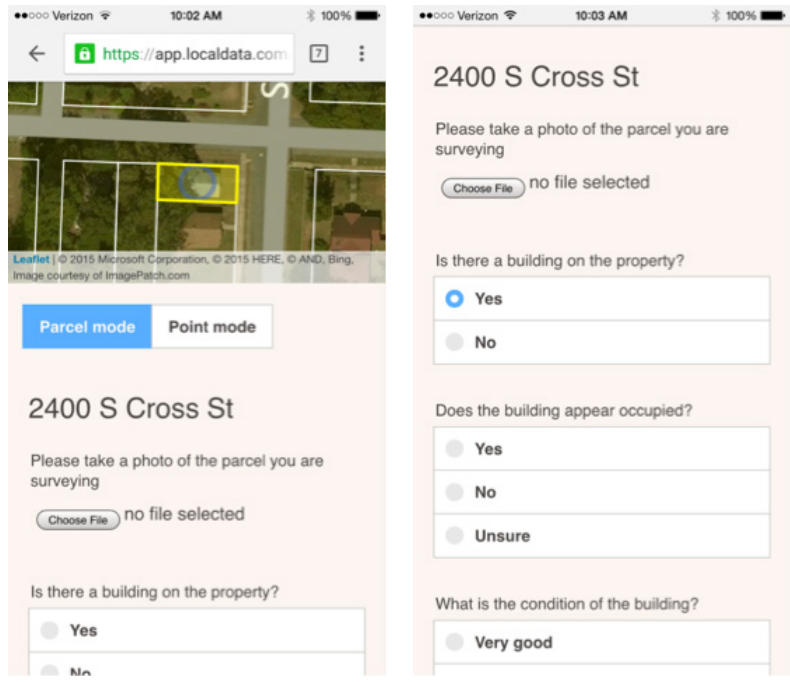

Figure 4. Screenshots of the web-based LocalData survey platform utilized in the Relocal projects

(Source: PlaceEconomics and LocalData, 2015)

In Cincinnati, Ohio, the Walnut Hills Redevelopment Foundation and the Cincinnati Preservation Association partnered to fund a Relocal analysis in the Walnut Hills neighborhood. Following the pilot study in Muncie, the Relocal analysis was tweaked to include tailored field survey questions and increased emphasis on the community priority survey. Members of the Cincinnati Preservation Association, the Cincinnati Preservation Collective, and the Walnut Hills Redevelopment Foundation with experience in architecture, planning, or preservation served as volunteers. The trained volunteers surveyed over 5,000 properties in three days using the same smartphone survey platform. The organizations in Walnut Hills are currently utilizing the dataset and parcel-level recommendations to guide short-term investment decisions and long-term partnerships.

And in Little Rock, Arkansas -- a city that on paper continues to grow due to annexation -- first ring older and historic neighborhoods have been suffering declining populations, vacant and 


\section{LocalData}

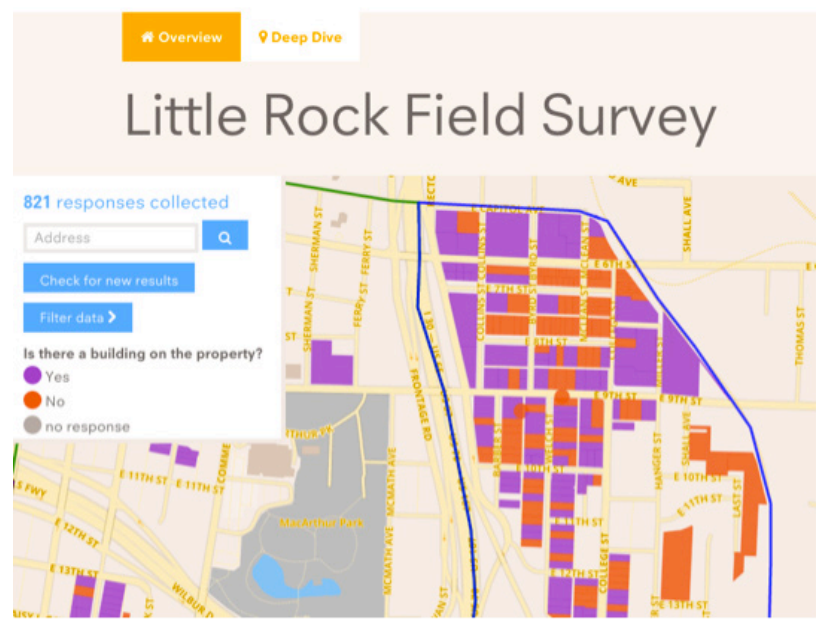

Figure 5. View of the back-end, quality-control analytics process during the Little Rock Relocal project

(Source: PlaceEconomics and LocalData, 2015)

neglected buildings, and economic disinvestment for decades. Relocal was applied to provide a strategic approach forward for vacant properties using the city's limited funding. Nearly 8,000 parcels were surveyed using the LocalData's rapid mobile survey platform and working with nearly 50 local resident volunteers. Of those parcels, nearly 2,400 were either vacant buildings or vacant lots, each of which received a parcel-level recommendation for how to move that property forward into productive use. Today, the City of Little Rock is implementing those recommendations in conjunction with the relevant city agencies and organizations on the ground.

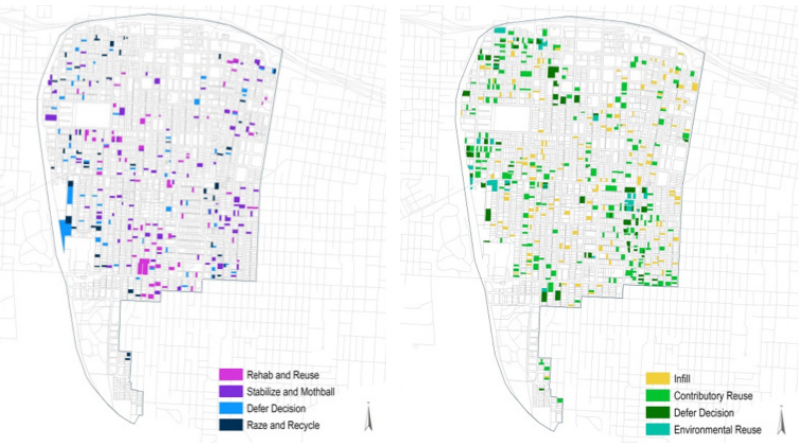

Figure 6. Relocal recommendation maps for vacant buildings (left) and vacant lots (right) in the neighborhood surrounding Central High School in Little Rock, Arkansas (Source: PlaceEconomics, 2015)

\section{ANALYSIS}

The above examples, with explicit focus on Relocal, exemplify shifts in data collection efforts that aim to measure and assess local assets in order to inform strategic rightsizing and planning decisions. They each utilize data to bridge the preservation field with planners, land banks, municipal governments, and other decision-makers. The examples addressed models and tools developing in response to rightsizing situations and tailored to the local conditions, funding sources, and groups involved. As legacy city landscapes continue to evolve, Relocal and other rapid mobile survey projects provide methodologies to build upon for future data collection efforts.

The Relocal tool uses smart technology to conduct an expedient field survey that recognizes the value of incorporating built environment characteristics such as architectural integrity and building condition into local planning decisions. While the DHRS and ScoutMuncie provide a preservation-focused data set to incorporate into other planning and data collection efforts, Relocal incorporates many of these same metrics into a comprehensive compendium of metrics that more holistically measures qualities of neighborhoods and properties. Importantly, a key element of the Relocal tool is its parcel-level recommendations derived from analysis. The DHRS and ScoutMuncie are models for incorporating preservation-focused data points into larger strategic planning efforts and are intended to help inform decision-making through data, but they do not make parcel-level recommendations.

Each of these projects serve as a model for how preservationists can proactively engage in legacy city demolition decision-making with partners across fields. By working with planning and land bank partners from the onset, the project and its findings were positioned for integration into planning efforts at its conclusion more easily. Both ScoutMuncie and DHRS developed in response to a specific set of conditions: the DHRS to a substantial sum of funding for demolition that had no preservation oversight as well as to provide a complementary data set for decision-makers, and ScoutMuncie to gather important data in Muncie that would inform decision-making by preservation, planning, code enforcement, and other city agencies. Both serve as highly applicable models for future adaptation.

Relocal, however, is a tool (rather than a model) that incorporates rapid mobile surveying with comprehensive data collection efforts along with recommendations that integrate historic resources into long-range planning, which includes myriad other neighborhood and livability metrics. It also takes into account context of local funding streams and connectivity to other local or regional plans. Like the DHRS and ScoutMuncie, Relocal's applications on the ground create opportunities for future comparisons and analysis as more rapid mobile survey and comprehensive data-based models emerge to enable informed planning for legacy cities.

\section{CONCLUSION}

Legacy cities are facing unprecedented challenges. Strategic rightsizing decisions require tactical utilization of data to support myriad neighborhood interventions across legacy cities and their neighborhoods. To stay relevant in the changing landscape of legacy cities, the field of historic preservation must develop innovative tools and partnerships to address these unique built environments. Tools like Relocal and models like the Detroit Historic Resource Survey and ScoutMuncie provide some examples for how to identify and leverage built assets to make smart reinvestment decisions moving forward. 


\section{REFERENCES}

Atassi, Leila. 2013. 'Proposed Federal Legislation Could Generate Millions Of Dollars For Demolition In Cleveland'. The Plain Dealer. http://www.cleveland.com/cityhall/index.ssf/2013/02/ proposed_federal_legislation_c.html.

Austen, Ben. 2014. 'The Post-Post-Apocalyptic Detroit'. The New York Times. http://www.nytimes.com/2014/07/13/magazine/the-post-post-apocalyptic-detroit.html?_r=0. Accessed Jan 7,2017

Bertron, Cara. 2012. Character Study Project: Developing A New Type Of Historic Resource Survey. Philadelphia: University of Pennsylvania School of Design.

Bertron, Cara. 2013. 'Rightsizing Right'. Forum 24 (4): 23-33.

Bertron, Cara, and Donovan Rypkema. 2015. Transforming Vacancy In Walnut Hills. PlaceEconomics.

Brachman, Lavea, and Alan Mallach. 2013. 'Op-Ed: 'Demolition' Is Not A Bad Word - Just Keep It Strategic'. Next City. http://nextcity.org/daily/entry/for-legacy-cities-demolition-isnot-a-bad-word-just-keep-it-strategic\#.Ujb0eQJ6Boc.email.

Bragg, Amy. 2014. 'Urgent Call To Action! Volunteers Needed For Critical Neighborhoods Survey - Preservation Detroit'. Preservation Detroit. http://preservationdetroit.org/urgent-call-to-action-volunteers-needed-for-critical-neighborhoods-survey/.

Broadbent, Kimberly A. 2015. Assessing The Impact Of Local Historic District Designation On Mortgage Foreclosure Rates: The Case Of Philadelphia. Philadelphia: University of Pennsylvania. http://repository.upenn.edu/cgi/viewcontent.cgi?article $=1164 \&$ context $=$ hp theses

Co.lucas.oh.us,. 2015. 'Lucas County, OH - Official Website - The Toledo Survey'. http://co.lucas.oh.us/index.aspx?NID=2783. Accessed Jan 7, 2017.

Dale, Brady. 2013. 'Chicago's Land Bank Will Use Big Data To Target Vacant Homes'. Next City. http://nextcity.org/daily/entry/ applying-big-data-to-vacants-and-other-steps-taken-by-chicagos-land-bank. Accessed Jan 3, 2017.

Davidson, Kate. 2013. 'States Divert Foreclosure Prevention Money To Demolitions'. Marketplace Economy. http://www. marketplace.org/topics/economy/states-divert-foreclosure-prevention-money-demolitions.

Department of Administration, Finance, Policy and Urban Affairs,. 2007. Mayor Brown's "5 In 5" Demolition Plan. Buffalo: City of Buffalo.

Detroit Blight Removal Task Force,. 2014. Every Neighborhood Has A Future... And It Doesn't Include Blight. .

Detroit. http://report.timetoendblight.org/index.html.

Discoverdenver.co,. 2015. 'DISCOVERDENVER.CO'. http:// www.discoverdenver.co/.

Evans, Emilie. 2014. 'Integrity, Character \& Intactness: A Preservation Survey Model For Legacy Cities'. Urban Infill 7: 75-79.

Evans, Emilie, Donovan Rypkema, and Briana Grosicki. A Way Forward: Strategies and Tools for Addressing Vacancy in Lit- tle Rock. February 2016. Findings from PlaceEconomics' Little Rock Relocal project.

Florida, Richard. 2012. 'What Draws Creative People? Quality Of Place'. Urban Land Magazine. http://urbanland.uli.org/ industry-sectors/what-draws-creative-people-quality-of-place/.

Huduser.org,. 2014. 'Vacant And Abandoned Properties: Turning Liabilities Into Assets | HUD USER'. http://www.huduser.org/ portal/periodicals/em/winter14/highlight1.html.

Griswold, Nigel G., and Patricia E. Norris. 2007. Economic Impacts Of Residential Property Abandonment And The Genesee County Land Bank In Flint, Michigan. Michigan State University Land Policy Institute. http://community-wealth.org/ sites/clone.community-wealth.org/files/downloads/report-griswold-norris.pdf.

KAPSZUKIEWICZ, WADE. 2015. 'Toledo Housing Survey Offers A Basis For Smart Use Of Tax Dollars'. The Blade. http:// www.toledoblade.com/Opinion/2015/06/07/Toledo-housingsurvey-offers-a-basis-for-smart-use-of-tax-dollars.html.

Kostyu, Paul E. 2008. 'Properties In City's Historical Districts Show Stability, Investment Opportunity In Roiled Market'. Columbus Business First. http://www.bizjournals.com/columbus/ stories/2008/12/08/focus1.html.

Legacycities.org,. 2015. 'Legacy Cities Partnership'. http:// www.legacycities.org. 4 Mar. 2015

Loveland Technologies. "Motor City Mapping." Motor City Mapping. Accessed Jan 20, 2017.

Mallach, Alan. 2012. Laying The Groundwork For Change: Demolition, Urban Strategy, And Policy Reform. Washington, D.C.: Brookings Metropolitan Policy Program.

Mallach, Alan, and Lavea Brachman. 2013. Regenerating America'S Legacy Cities. Policy Focus Report. Cambridge: Lincoln Institute of Land Policy. https://www.lincolninst.edu/pubs/2215 Regenerating-America-s-Legacy-Cities.

Mallach, Alan. 2014. 'Hardest Hit Funds Demolition Policy Change On Track To Become A Boon For Distressed Communities. Blog. Community Progress Blog. http://www. communityprogress.net/blog/federal-policy-change-leads-results-ground-hardest-hit-funds-demolish-derelict-houses.

Mason, Randall F. 2009. 'Preservation Planning In American Cities'. Forum Journal Winter: 39.

Mayes, Tom. 2015. 'Why Do Old Places Matter? Community'. Blog. Preservation Leadership Forum. http://blog.preservationleadershipforum.org/2015/03/10/old-places-community/\#. VX2dNVVViko.

National Trust for Historic Preservation | Preservation Green Lab,. 2014. Older, Smaller, Better: Measuring How The Character Of Buildings And Blocks Influences Urban Vitality. Seattle: National Trust for Historic Preservation. http://www.preservationnation.org/information-center/sustainable-communities/ green-lab/oldersmallerbetter/report/NTHP_PGL_OlderSmallerBetter_ReportOnly.pdf.

Nps.gov,. 2015. 'Section II: How To Apply The National Register Criteria For Evaluation, National Register Of Historic Places 
Bulletin (NRB 15)'. Accessed Jan 10, 2017. http://www.nps.gov/ $\mathrm{nr} /$ publications/bulletins/nrb15/nrb15_2.htm

Oaks, Michele. 2014. 'Historic Resource Survey With Mobile Technology: A Case Study In Alexandria, Virginia'. Blog. Preservation Forum Blog. http://blog.preservationleadershipforum. org/2014/08/21/historic-resource-survey/\#.VX4th1VVikp.

Placeeconomics.com,. 2015. 'Rightsizing'. Accessed Jan 11, 2017.http://www.placeeconomics.com/rightsizing.

Planning.org,. 2015. 'Characteristics And Guidelines Of Great Neighborhoods'. Accessed Jan 9, 2017. https://www.planning. org/greatplaces/neighborhoods/characteristics.htm.

Powe, Mike. 2014. 'Big Data: A New Frontier In Historic Preservation?'. Blog. Preservation Leadership Forum. http://blog. preservationleadershipforum.org/2014/03/04/big-data-osb/\#. VX4uOVVVikq.

Preservation.org. 2015. 'Economic Benefits Of Preservation'. Accessed Jan 10, 2017. http://www.preservation.org/rypkema. htm

Preservation Action,. 2013. 'Hardest Hit Fund Ok'D For Demolition Costs; Tax Reform Threatens Historic Tax Credits; Rep. Garamendi Joins Caucus'. http://www.preservationaction.org/ hardest-hit-fund-used-for-demolition-tax-reform-threat-htc-garamendi-joins-caucus/.

Rightsizing Cities Initiative, PlaceEconomics,. 2015. Stronger Neighborhoods Through Strategic Decisions: Relocal Tool. PlaceEconomics. Accessed Jan 7, 2017.

Rypkema, Donovan, and Briana Paxton. 2015. Historic Preservation: Part Of The DNA Of Pittsburgh. PlaceEconomics. Accessed Jan 9, 2017

Scoutmuncie. 2016. Results, Survey Map and Data. Accessed January 20, 2017. https://scoutmuncie.wordpress.com/.

The Advisory Council on Historic Preservation,. 2014. Managing Change: Preservation And Rightsizing In America. The Advisory Council on Historic Preservation. http://www.achp.gov/ RightsizingReport.pdf.

The American Assembly,. 2011. Reinventing America's Legacy Cities: Strategies For Cities Losing Population. The American Assembly. http://americanassembly.org/publications/reinventing-americas-legacy-cities-strategies-cities-losing-population.

Western Reserve Land Conservancy,. 2015. Estimating The Effect Of Demolishing Distressed Structures In Cleveland, OH, 2009-2013: Impacts On Real Estate Equity And Mortgage-Foreclosure. Cleveland: Thriving Communities Institute. Accessed June 3. http://www.thrivingcommunitiesinstitute.org/documents/FinalReportwithExecSummary_modified.pdf.

Williams, Timothy. 2013. 'Blighted Cities Prefer Razing To Rebuilding'. The New York Times. http://www.nytimes. com/2013/11/12/us/blighted-cities-prefer-razing-to-rebuilding. html? r=0. 